\title{
Progressive Chemistry.
}

THE Journal of Chemical Education, a beautifully printed and illustrated monthly magazine of some two hundred pages, conveys a striking and even startling impression of the popularity and progress of chemical studies in the United States. The journal, which costs two dollars fifty cents per annum, is the official organ of the Division of Chemical Education of the American Chemical Society, and its aim may be expressed in terms practically identical with those which are applied in the January issue to the closely related. Chemical Foundation Inc., that is, "the advancement and maintenance of chemical education in the United States to the plane where we shall have not only the best chemistry teachers and methods of teaching this science in the world, but also have the most enlightened lay people who will appreciate the importance of the application of chemistry in all phases of life and industry".

The staff of the journal includes six departmental editors and more than sixty contributing editors; in addition to the latter there are sixteen abstractors. Among the dozen foreign editors we notice the names of Sir James Irvine (St. Andrews), Prof. F. G. Donnan (London), Prof. K. Freudenberg (Heidelberg), Prof. E. Cohen (Utrecht), and Prof. W. D. Treadwell (Zurich). The thorough way in which the Division of Chemical Education of the American Chemical Society has set about its duties is evident from the lists of committees, members of the Senate of Chemical Education, and local organisations operating in the various States. The twelve committees upon the current list are concerned with such subjects as aids to visual instruction in chemistry, chemical education of the non-collegiate type, correlation of high-school and college chemistry, labels, professional spirit among high-school teachers, research problems, and women's club study course in chemistry.
The editorial article of the January issue contains some interesting references to Benjamin Silliman (1779-1864), the first professor of chemistry at Yale, who took up the duties of the chair in 1804 . "America's first great scientific publicist", in his early days at Philadelphia, was acquainted with Hare and Priestley the chemists, Wistar the anatomist, Barton the botanist, and Seybert the mineralogist; he therefore links these names with those of his own eminent pupils of a later age, among them " Dana, world-renowned geologist and mineralogist; Brush, whose exhaustive mineralogical chemical studies are authoritative everywhere; Johnson, pioneer leader in chemistry applied to agriculture; Willard Gibbs, first among physical chemists of modern times; $T$. Sterry Hunt, profound in chemical philosophy and theory". There are articles on the tung-oil tree (with some good coloured plates), the teaching of electrochemistry (a symposium presented before the American Electrochemical Society at Toronto, in 1929), educational activities of Mellon Institute, and chemical warfare.

Among other features, there are contests for students, notices of new books and scientific articlos in magazines, and illustrated abstracts of interesting papers from current chemical and educational journals -including a section entitled " Keeping up with Chemistry". "One of the hardest and most disappointing things is to endeavour to retain an active interest in chemistry after one has graduated," is the complaint of a writer in the December Alchemist, the official organ of the Glasgow University AI. chemists' Club. This very real difficulty would be overcome if chemists in Great Britain could develop sufficient enterprise to publish a British counterpart to the lively and stimulating American Journal of Chemical Education, which is now in its seventh year.

\section{Stellar Velocities and Stellar Physics.}

$\mathrm{A}^{\mathrm{T}}$ the annual meeting of the Royal Astronomical A. C. D. Crommelin, delivered an address on the work of Dr. J. S. Plaskett, director of the Dominion Astro. physical Observatory, Victoria, B.C., to whom the Gold Modal of the Society has this year been awarded "for his valuable observations of stellar radial velocities and the important conclusions derived from them ". The award, said Dr. Crommelin, was made " not for any single outstanding result, but in recognition of the high merit of a long series of researches, extending over a quarter of a century, and marked throughout by a painstaking striving after the highest accuracy attainable, combined with an alertness in discerning problems of stellar motion and stellar physics to which the powerful observational means available might most suitably be applied ".

Dr. Plaskett's astronomical career began in 1905 at the Ottawa Dominion Observatory, where he was placed in charge of the Department of Astrophysics. His early work included the determination of stellar radial velocities for various purposes, but the instruments at his disposal would not permit of an extension of the work beyond stars of the fifth magnitude. It soon became clear to him that the greatest need in this work was the examination of fainter stars, and the possibility of obtaining a telescope of larger aperture than those he had up to that time employed began to oceupy his thoughts. During a visit to Mount Wilson in 1910 to attend a meeting of the Solar Union, the desire to obtain such an instrument was greatly intensified by an appeal from
Prof. Campbell for co-operation in determining the radial velocities of the fainter stars. Dr. Plaskett conceived the idea that Canada might distinguish herself among the nations by erecting a giant reflector for spectroscopic research, and on returning to Ottawa he laid his scheme before his director, Dr. W. F. King, who endorsed it with enthusiasm. Mainly through Dr. Plaskett's efforts, the 73-inch telescope-the largest in the British Empire and the second largest in the world-was erected at Victoria, and he was appropriately appointed as the first director of the new observatory established at the same time.

Of the large amount of important work which has been done both by Dr. Plaskett himself and by assistants under his direction, arising from the extended programme of radial velocity determinations thus made possible, the outstanding results relate to the study of the high temperature $O$-type stars, the character of the interstellar calcium cloud, and the rotation of the galaxy. Among the O-type stars, particular interest attaches to 'Plaskett's star', a binary the components of which are respectively' at least 86 and 72 times as massive as the sun. These are easily the largest figures for stellar masses so far found in our sidereal system. Dr. Plaskett assumed, in the absence of evidence to the contrary, that the stars, as seen from the earth, do not eclipse one another in their mutual revolution, but Dr. Crommelin gave reasons for doubting this. If it should be established from variation of the light that eclipses take place, more precise values of the masses will be obtainable. 
The systematic investigation of the 'stationary' ionised calcium lines in the spectra of hot stars which Dr. Plaskett carried out led to the first clear demonstration that the material responsible for these lines had no motion with respect to our system of stars. His earlier suggestion that it was originally discharged by the hot stars and came to rest some distance away from them probably needs modification in view of the evidence for Eddington's hypothesis that the matter is distributed throughout interstellar space, and indeed Dr. Plaskett, in a very recent paper, has himself given some of the strongest evidence for the latter view by showing, from the consideration of three separate groups of stars, that the average distance of the cloud is half that of the stars in the spectra of which its lines appear. It must be remembered also that Eddington's work in this connexion would not have been possible but for the thoroughness and accuracy of Plaskett's original investigation.

The idea that the galaxy is rotating is not a new one, but the evidence for some former ideas on this matter is now known to be spurious. The subject has lately come to the fore again through the realisation that our stellar system is probably a spiral nebula, and therefore is in all probability rotating in the manner which the appearance of those bodies forces us to admit. Specific evidence for the rotation recently came from Oort and Lindblad, and Dr. Plaskett at once perceived that his radial velocity measurements could throw an important light on the matter. He analysed the motions of the distant stars-those of types $B$ and $O$, of which he had made a special study - and was able to show that they gave clear indications of rotation about a centre in galactic longitude $324 \cdot 5^{\circ}$, which agrees with the position given by Oort and also with that found by Shapley for the centre of the galactic system from totally different considerations based on the distribution of globular clusters. The centre of the galaxy is near the junction of the constellations Sagittarius, Ophiuchus, and Scorpio, in a 'rift' between two branches which is probably caused by obscuring matter hiding from us what would otherwise be the brightest part of the Milky Way. Dr. Plaskett's contributions to the elucidation of this problem have been characterised by the solidity and thoroughness which he has shown throughout his career, and his results, however their interpretation may vary, are permanent.

Dr. Plaskett, who has been invited to give the George Darwin lecture of the Royal Astronomical Society, has chosen as his subject "The High Temperature Stars". The lecture will be delivered on May 9, and will contain some hitherto unpublished material on these important bodies.

\section{River Flow Records in the Ness Basin, Scotland.}

$\mathrm{T}^{\mathrm{o}}$ those interested for scientific and technical reasons in the availability of trustworthy data respecting river flow in Scotland, the appearance of two unostentatious pamphlets, ${ }^{1}$ or monographs, containing records during recent periods of the Rivers Garry and Moriston, both in the Ness Basin, Inverness-shire, will be welcome not merely for the records themselves and the information they afford at the moment, but also as indicating the inauguration of a series of observations which, if continued and extended over a period of years, cannot fail to be of considerable value when the time arrives for dealing with questions of river development.

Capt.W.N.McClean, at his own pains and expense, in conjunction with some voluntary helpers, has set on foot the systematic collection of hydrological data which no public or authoritative body in Scotland (or indeed in Great Britain) is empowered or disposed to undertake. It is true that the Scottish Meteorological Department in Edinburgh has shown itself helpful in certain directions, and that it receives rainfall returns and provides general supervision over their collection, but the brunt of river gauging work falls at present on the private investigator. "River Flow Records", the organisation of Capt. McClean and his fellow-workers, is therefore an undertaking in the public interest which is deserving of acknowledgment for its altruistic labours. The quarterly reports, which are on sale at a nominal figure, are distributed not only to all who have given facilities for, or assistance in, the taking of measurements, but also "to others who it is hoped will help in assuring continuous measurements of the water resources of the country".

The two rivers which form the subject of the monographs have equivalent catchment areas, but some appreciable variation in rainfall. The River Moriston has a catchment area above the gauging section of 149 square miles, and the River Garry an area of 148 square miles. For both rivers, therefore, a flow of 400 cusecs is equal to 0.1 inch per day on the catch-

I River Flow Records, Ness Basin : River Moriston and River Garry. Reports on River Flow, July to September $1929 . \quad$ Each 4 pp. +3 tables. (Parliament Mansions, Victoria Street, S.W.1.) 1s. 6d. each. ment area. The flow-off of the Garry, however, is considerably greater than that of Moriston on account of the larger area under heavy rainfall at the headwaters of the former. For the two months of August and September in the period under review the ratio was as much as 3 to 2 .

The comparison of flow-off and rainfall for the Moriston covers a period of a little more than nineweeks in the autumn of 1929 (July 27-Sept. 30) based on actual measurements of flow made between Sept. 13 and Sept. 26. These few measurements, Capt. McClean considers, are sufficient to enable a fair estimate to be made of the flow near Invermoriston from a moderately low river to a considerable flood, and permit of a rough prediction of flow for any recorded river height. In default of more extended observations, the figures in the tables undoubtedly will be helpful, but it is obvious that there is need to supplement and compare them with later readings over a longer period, in order to increase the range, to eliminate errors, and to secure closer approximations.

In the case of the Garry, measurements of flow were made between Aug. 27 and Sept. 11, 1929. Here, too, the records are for a very short period, but the author points to the observations which he kept of water level and rainfall during the three years 1913-15, the results of which were published in the Proceedings of the Institution of Water Engineers for 1927. The present records, therefore, are a resumption of the work previously carried on and unfortunately interrupted. It is of interest to note that the flow of the Garry does not change with the rapidity of that of the Moriston on account of the long narrow exit from Loch Garry. The loch rises gradually and has risen as much as 20 feet, storing at that level the equivalent of 3 inches of rainfall over its feeding area. As a consequence, floods below the loch are delayed and spread over a long period.

It is understood that not only are the present records to be continued, but also that similar readings and measurements are contemplated for other streams in the Ness Basin, including the Rivers Oich and Ness. BRysson CunNinghaM.

No. 3148, VoL. 125] 